\title{
Thermal Stability and Kinetic Study of Isotactic Polypropylene/Algerian Bentonite Nanocomposites Prepared via Melt Blending
}

\author{
Fayçal Benhacine, Farida Yahiaoui, and Assia Siham Hadj-Hamou \\ Laboratoire des Matériaux Polymères, Département de Chimie Macromoléculaire, Faculté de Chimie, \\ Université des Sciences et de la Technologie Houari Boumediene, BP 32, El Alia, 16111 Alger, Algeria
}

Correspondence should be addressed to Assia Siham Hadj-Hamou; hadjhamouassia@yahoo.fr

Received 16 February 2014; Revised 18 March 2014; Accepted 18 March 2014; Published 16 April 2014

Academic Editor: Yves Grohens

Copyright (C) 2014 Fayçal Benhacine et al. This is an open access article distributed under the Creative Commons Attribution License, which permits unrestricted use, distribution, and reproduction in any medium, provided the original work is properly cited.

Isotactic polypropylene (iPP)/bentonite nanocomposites were prepared via melt blending using bentonite clay originated from Maghnia (Algeria). This clay was, at a first stage, used in its pure form (PBT) and then organically modified by Hexadecyl ammonium chloride (OBT). The effect of Maghnia bentonite dispersion on the iPP matrix was investigated by X-ray diffraction (XRD) and transmission electronic microscopy (TEM). DSC results evidenced that unmodified or organomodified bentonite can act as a nucleating agent increasing the rate of crystallites formation. Moreover, a thermogravimetry analysis confirmed a significant enhanced thermal stability of IPP/clay nanocomposites compared to pure IPP. The Flynn-Wall-Ozawa and Tang methods were applied to determine the activation energy $E_{a}$ of the degradation process. The apparent activation energy $E_{\alpha}$ of thermal degradation for IPP/clay nanocomposites was much higher than that of virgin iPP. Comparatively to PBT, results indicate that OBT has an important effect on pure iPP thermal stability. Tensile modulus, tensile strength, and elongation at break were also measured and compared with those of pure iPP.

\section{Introduction}

Isotactic polypropylene (iPP) is one of the most interesting commodity thermoplastic accounting for about $20 \%$ of the total world's polyolefin production, not only for its balance of physical and mechanical properties but also for its environmental friendliness (recyclability) and low cost. It is widely used in many applications, such as fibers, films for food packaging, bottles production, and tubes.

Isotactic polypropylene (iPP)/clay composites are among the pioneer researched nanocomposites because iPP is one of the most widely used polyolefins, and its properties are greatly affected by clay dispersion in the polymer [1-10]. Many researches were reported on preparation and characterization of polypropylene (iPP)/clay nanocomposites, focusing on the dispersed morphology of clay particles [11-14].

Polymer degradation is the purpose of many researches on plastic waste management. The knowledge of degradation kinetics of polymers is important for modeling the degradation process. Several mechanisms were proposed to describe thermal and flame properties of polymer/clay nanocomposites. Generally, the barrier effect of clay layers for heat and volatiles plays a key role in these enhancements. Kinetic data reflect that improvement of thermal stability of polymer/clay nanocomposites is associated with an increase in the activation energy of their degradation; this is explained by the barrier effect developed by clay layers [8, 15-17].

In this survey iPP was mixed in the melt state with pure and organically modified Maghnia bentonite to obtain nanocomposite. Nanoclay dispersion and intercalation mechanisms will be studied on iPP stability and thermal and mechanical properties.

\section{Experimental Part}

2.1. Materials. Commercial grades isotactic polypropylene (iPP), iPP 05-RF03-0577 C-2807 AQ4, was supplied by Oriental Petrochemicals, Saudi Arabia. 
Bentonite (PBT) originated from Maghnia (Algeria) supplied by Bentonite Company of Algeria and analyzed by ENOF Central Laboratory (National Company of Nonferrous Mining Products and Useful Substances). This clay which contains $\mathrm{SiO}_{2}$ (55-65\%), $\mathrm{Al}_{2} \mathrm{O}_{3}$ (12-18\%), $\mathrm{Fe}_{2} \mathrm{O}_{3}$ (1-3\%), $\mathrm{Na}_{2} \mathrm{O}(1-3 \%), \mathrm{CaO}(1-5 \%), \mathrm{K}_{2} \mathrm{O}(0.76-1.75 \%)$, and $\mathrm{MgO}(2-$ $3 \%)$ was initially used in its pure form and then organically modified byHexadecyl ammonium chloride (OBT).

Hexadecyl ammonium chloride was prepared as already stated [18] by mixing adequate amounts of hexadecylamine with concentrated $\mathrm{HCl}$ in $300 \mathrm{~mL}$ of distilled water added to bentonite clay (OBT) dispersed into hot distilled water at $80^{\circ} \mathrm{C}$ under vigorous stir for $1 \mathrm{~h}$. The mixture was then filtered and washed with water in ethanol (50/50 vol\%) until negative chloride test was obtained using $\mathrm{AgNO}_{3}$.

Hexadecyl ammonium exchanged clay (OBT) was then dried at $80^{\circ} \mathrm{C}$ for 3 days in a vacuum oven.

2.2. Blending. Melt blending of virgin iPP polymer and $5 \%$ in weight of pure bentonite (PBT) or organically modified bentonite (OBT) was conducted using a twin-screw microextruder (5 and 15 microcompounder DSM Xplore) and mixing process parameters ( $60 \mathrm{rpm}$ screw speed, $10 \mathrm{~min}$ mixing time, and temperature profile: $175-180-180^{\circ} \mathrm{C}$ ) were modulated to optimize material final properties.

\subsection{Characterizations}

2.3.1. X-Ray Diffraction. X-ray diffraction patterns were obtained from a Philips PW3710 diffractometer in $2 \theta$ (1.5$50^{\circ}$ ) range. The monochromatic radiation applied was $\mathrm{Cu} \mathrm{K} \alpha$ (1.5406 $\AA$ ) operating at $35 \mathrm{kV}$ and $25 \mathrm{~mA}$.

2.3.2. Transmission Electronic Microscopy (TEM). As a complementary technique to XRD, TEM was used to investigate the morphology of the elaborated materials using a JEOL 1200EXII microscope operating at $100 \mathrm{kV}$.

\subsubsection{Thermal Characterization}

DSC Analysis. Differential scanning calorimetry (DSC) measurements were made on a 204 F1 Phoenix (Netzsch Company). All measurements were carried out in nitrogen atmosphere. The samples were heated from -70 to $200^{\circ} \mathrm{C}$, held in the molten state for $2 \mathrm{~min}$ to eliminate the influence of thermal history, and then cooled at a rate of $10^{\circ} \mathrm{C} / \mathrm{min}$ to room temperature. Both endothermal flow and exothermal flow were recorded. From these scans the melting temperature (Tmp) and the heat of fusion $\left(\Delta H_{m}\right)$ of the composites were measured. The degree of crystallinity $\chi_{c}$ was calculated under the assumption in which the heat of fusion is proportional to the crystalline content, as $\chi=\Delta H_{m} /\left(1-w_{\text {clay }}\right) \Delta H_{m}^{0}$, where $\Delta H_{m}^{0}$ is the enthalpy of fusion of completely crystalline sample and taken in this work as $146 \mathrm{~J} / \mathrm{g}$ [19] and $w_{\text {clay }}$ is the weight fraction of nanoclay in the nanocomposite.

TGA Analysis. Thermogravimetry analysis (TGA) was conducted on a TA Instruments TGA Q500 using an ultrahigh purity (UHP) nitrogen atmosphere. The samples (films of $10.0 \mathrm{mg}$ ) were heated from 25 to $600^{\circ} \mathrm{C}$ at $5,10,20,30$, and $40^{\circ} \mathrm{C} / \mathrm{min}$ heating rates under nitrogen flow.

Mechanical Tests. Tests specimens for tensile measurements were prepared from $1 \mathrm{~mm}$ thick plates. Tensile modulus, tensile strength, and elongation at break were measured in a tensile Instron Zwick/Roell Z 100. Tester was set at $200 \mathrm{~mm} \mathrm{~min}^{-1}$ strain rate.

\section{Kinetic Models}

Many kinetic models were proposed to simplify the general kinetic equation and determine the degradation process parameters.

Reaction rate in TGA studies can be defined as the variation of conversion degree to time or temperature where the degree of conversion $(\alpha)$ is calculated in terms of mass loss according to the following equation:

$$
\alpha=\frac{W_{0}-W_{t}}{W_{0}-W_{\infty}}=\frac{\Delta W}{\Delta W_{\infty}},
$$

where $W_{0}, W_{t}$, and $W_{\infty}$ are, respectively, weight at the beginning of the degradation step, actual weight at each point of the curve, and the final weight measured after consideration of the specific degradation process. Conversion rate for a kinetic process can be typically indicated as the result of two contributions: the first one is the temperature which affects the kinetic constant and the second one is the concentration of reactive species. Therefore, the kinetic information can be extracted from dynamic experiments by means of various methods. All kinetic studies assume that isothermal conversion rate, $d \alpha / d t$, is a linear function of a temperature-dependent rate constant $k$ and a temperatureindependent function of the conversion $\alpha$; that is,

$$
\frac{d \alpha}{d t}=k f(\alpha)
$$

where $f(\alpha)$ depends on the particular decomposition mechanism.

According to Arrhenius,

$$
k(t)=A \exp \left(-\frac{E_{a}}{R T}\right),
$$

where $A$ is preexponential factor, $E_{a}$ is the apparent activation energy $(\mathrm{kJ} / \mathrm{mol}), R$ is the gas constant $(8.314 \mathrm{~J} / \mathrm{mol} \mathrm{K})$, and $T$ is the absolute temperature $(\mathrm{K})$. According to the complexity of the multiple degradation reactions, the function $f(\alpha)$ is generally very complex and it is not possible to solve the differential equation (1) leading to the necessity to introduce some simplifications to determine the kinetic parameters. A simple expression proposed for $f(\alpha)$ is the use of the $n$ thorder model represented in the following equation:

$$
f(\alpha)=(1-\alpha)^{n},
$$


where $n$ is the reaction order. By inserting (3) and (4) into (2), we can obtain

$$
\frac{d \alpha}{d t}=A(1-\alpha)^{n} \exp \left(-\frac{E_{a}}{R T}\right) .
$$

For a dynamic TGA process, introducing the heating rate, $\beta=$ $d T / d t$, into (1), (2) is obtained as follows:

$$
\frac{d \alpha}{d T}=\left(\frac{A}{\beta}\right) \exp \left(-\frac{E}{R T}\right)(1-\alpha)^{n} .
$$

Integration of this equation from an initial temperature, $T_{0}$, corresponding to a degree of conversion, $\alpha_{0}$, to the peak temperature $T_{p}$, where $\alpha_{0}=\alpha_{p}$, gives kinetic methods used in evaluating activation energy in this study. Consider the following:

$$
\int_{\alpha_{0}}^{\alpha p} \frac{d \alpha}{(1-\alpha)^{n}}=\frac{A}{\beta} \int_{T_{0}}^{T p} e^{-(E a / R T)} d T .
$$

If $T_{0}$ is low, it may be reasonably assumed that $\alpha_{0}=0$ and considering there is no reaction between 0 and $T_{0}$, one has

$$
\int_{0}^{\alpha p} \frac{d \alpha}{(1-\alpha)^{n}}=\frac{A}{\beta} \int_{0}^{T p} e^{-(E a / R T)} d T
$$

3.1. The Ozawa-Flynn-Wall (OFW) Method (See [20, 21]). This method represents a relatively simple method to determine activation energy directly from weight loss versus temperature data obtained at several heating rates. Equation (7) is integrated using Doyle's approximation, and the result of integration after taking logarithms is

$$
\ln \beta=-1.052 \frac{E_{a}}{R T}+\text { const, }
$$

where $\beta, A, E$, and $T$ have the known meanings. This is one of the integral methods that can determine activation energy without knowledge of reaction order. It is used to determine activation energy for given values of conversion. Activation energy for different conversion values can be calculated from $\ln \beta$ versus $1 / T$ plot.

3.2. The Tang Method (See [22]). New equation for the evaluation of nonisothermal kinetic parameters has been proposed by Tang and it can be written in the following form:

$$
\begin{aligned}
\ln \frac{g(\alpha)}{T^{1.89466100}}= & -1.00145033 \frac{E_{\alpha}}{R T_{\alpha}}+\ln \left[\frac{A_{\alpha} E_{\alpha}}{\beta R}\right] \\
& +3.63504095-1.89466100 \ln E_{\alpha} .
\end{aligned}
$$

The corresponding equation has been modified to be applied in an isoconversional way and is given by the following equation:

$$
\begin{aligned}
\ln \frac{\beta}{T^{1.89466100}}= & 1.00145033 \frac{E_{\alpha}}{R T_{\alpha}}+\ln \left[\frac{A_{\alpha} E_{\alpha}}{R}\right]-\ln g(\alpha) \\
& +3.63504095-1.89466100 \ln E_{\alpha},
\end{aligned}
$$

where $\beta$ is the heating rate, $\alpha$ is the extent of conversion (weight of materials volatilized/initial weight of materials), $R$ is the universal gas constant, and $g(\alpha)$ is a mathematical function whose form is related to the reaction mechanism. $E_{\alpha}, A_{\alpha}$, and $T_{\alpha}$ are, respectively, the activation energy, the preexponential factor, and the absolute temperature related to a given extent of conversion.

Plotting $\ln \left[b / T^{1.89466100}\right]$ versus $1 / T$, the activation energy $E_{\alpha}$ is obtained from the slope.

\section{Results and Discussion}

4.1. Characterizations of Pure and Organomodified Maghnia Bentonite. Prior to its use as nanofiller in iPP matrix, OBT was first characterized by FTIR spectroscopy and X-ray diffraction to evidence its organic modification.

Figure 1 illustrates FTIR spectra of pure and organically modified bentonite clay.

Pure bentonite clay shows characteristic vibration bands located at $3630 \mathrm{~cm}^{-1}$ (OH stretching from lattice hydroxyl), $1032 \mathrm{~cm}^{-1}$ (Si-O stretching), and $469 \mathrm{~cm}^{-1}$ (Al-O stretching). Those appearing around $920 \mathrm{~cm}^{-1}$ and $800 \mathrm{~cm}^{-1}$ characterize the tetra- and octahedral layers of bentonite clay [18].

In addition to the characteristic absorption bands of PBT, organomodification of Maghnia bentonite by Hexadecyl ammonium salt is evidenced by the presence of the band at $3625 \mathrm{~cm}^{-1}$ and by the appearance of new bands at $2925 \mathrm{~cm}^{-1}$, $2850 \mathrm{~cm}^{-1}$, and $1473 \mathrm{~cm}^{-1}$ characteristic of salt [18].

\subsection{Morphological Characterization}

4.2.1. X-Ray Diffraction. The degree of intercalation of PBT and OBT with iPP matrix was first analyzed by X-ray diffraction. Figure 2 displays XRD patterns of PBT, OBT, $\mathrm{iPP} / \mathrm{PBT}$, and iPP/OBT hybrids containing $5 \%$ in weight of nanoclay. The XRD pattern of PBT showed a peak at approximately $2 \theta=6^{\circ}$ corresponding to a basal spacing of $1.47 \mathrm{~nm}$, whereas a strong peak at $2 \theta=3^{\circ}$ (a basal spacing of $2.94 \mathrm{~nm}$ ) and a weak peak at $2 \theta=5.40^{\circ}$ are noticed with OBT. This indicates that clay layers are widely separated by Hexadecyl ammonium ions and that a portion of clay layer was not intercalated.

As shown in Figure 2, the presence of PBT in iPP appeared as a weak peak at a lower angle $\left(2 \theta=3.18^{\circ}\right)$ corresponding to a $d$-spacing of $2.77 \mathrm{~nm}$, which supposes the formation of an intercalated nanocomposite. The weak peak noticed at $2 \theta=6.0^{\circ}(d=1.47 \mathrm{~nm})$ with this nanocomposite also supposes that some clay layers are not totally intercalated by the polymer chains.

Insertion of $\mathrm{PP}$ chains in the interlayer spacing of OBT clay is evidenced from the shift of the characteristic XRD peak of OBT within iPP polymer to a lower angle than the one of OBT clay, resulting in an increase of $d$-spacing as $2 \theta=2.62^{\circ}$ corresponding to $(d=3.37 \mathrm{~nm})$, due to the large $d$-spacing of the clay, and enabling intercalation of polymer chains between clay layers.

Furthermore, incorporation of nanoparticles into the iPP matrix can cause changes in polymer crystallization rate 


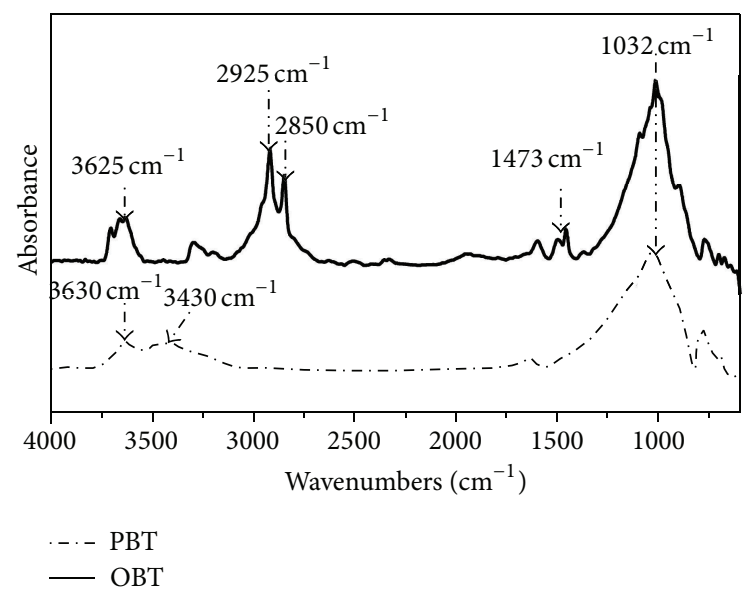

FIGURE 1: FTIR spectra of pure bentonite (PBT) and organomodified bentonite (OBT).

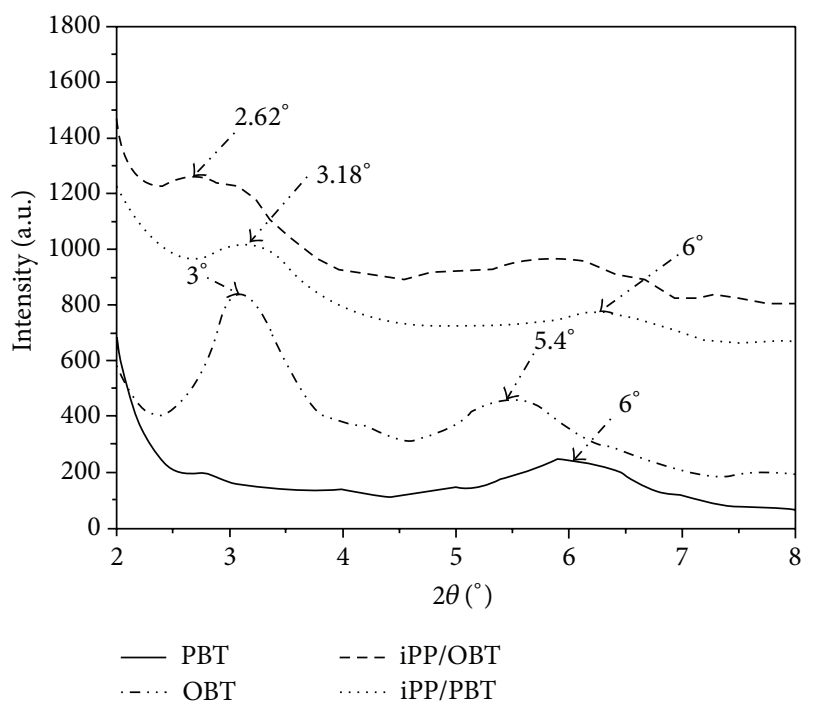

Figure 2: Wide angle X-ray diffraction patterns (XRD) of PBT, OBT, $\mathrm{iPP} / \mathrm{PBT}$, and $\mathrm{iPP} / \mathrm{OBT}$ materials.

and even induce changes in its crystal structure $[23,24]$. To examine this possibility, X-ray diffraction measurements were performed. XRD spectra of pure iPP polymer exhibit distinct $\alpha$-crystalline diffraction peaks at $2 \theta=14.5^{\circ}, 17.3^{\circ}$, $19.0^{\circ}, 22^{\circ}$, and $24.4^{\circ}$ (Figure 3 ). XRD results showed that the $\alpha$-crystalline form dominates for the two hybrid materials, meaning that the addition of PBT or OBT does not affect the crystal form of the final iPP molecules. Compared with XRD curves of pure iPP, diffraction peaks $(040,130$, 111, and 060) for the two iPP/PBT and iPP/OBT systems shifted slightly to lower angles and increased their relative intensity. A possible reason is that the addition of bentonite promotes the nucleation and growth of iPP crystals in an essential way and perfects the $\alpha$-crystalline form. In addition to the features associated with $\alpha$-form, only the introduction of $5 \mathrm{wt} \%$ OBT nanoparticles produces another peak at $2 \theta$ value

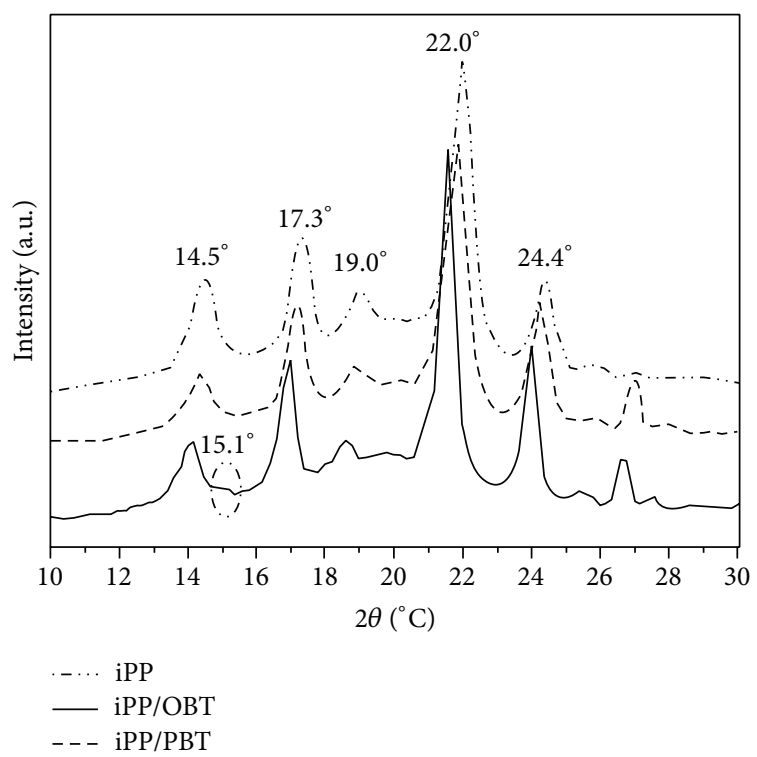

FIgURE 3: XRD curves of pure iPP and its iPP/Maghnia bentonite nanocomposites.

of $15.1^{\circ}$ indicating that both monoclinic $\alpha$ and trigonal $\beta$-form exist in this composite $[25,26]$.

4.2.2. Transmission Electronic Microscopy (TEM). A complementary characterization was carried out by TEM. Typical TEM micrograph of iPP/OBT, illustrated in Figure 4(a), confirmed in agreement with XRD the formation of mainly intercalated nanocomposite structures evidenced at high magnification by the presence of stacked layers randomly dispersed in the polymer matrix. However, the micrograph of iPP/PBT (Figure 4(b)) showed the presence of a limited number of intercalated stacks as well as weakly intercalated agglomerates coexisting with a significant fraction of clay agglomerations.

\subsection{Thermal Characteristics}

4.3.1. DSC Analysis. A DSC analysis was carried out to investigate the effect of PBT or OBT on the melting and crystallization behaviours of iPP polymer. It is known that isotactic polypropylene can crystallize in three forms: the monoclinic form, the trigonal form, and the triclinic form [27]. The $\alpha$ phase is the principal constituent in normal processing conditions.

Figure 5 depicts the DSC melting curves of iPP and its iPP hybrids composites. It is obvious that iPP sample presents a single melting peak at about $160^{\circ} \mathrm{C}$ attributed to the melting of $\alpha$-iPP [28].

According to DSC measurements gathered in Table 1, it seems that PBT has no effect on the iPP melting behavior. The melting temperature of the dominant crystal fraction in the $\mathrm{iPP} / \mathrm{PBT}$ composite remains constant indicating that PBT does not change the iPP crystal organization. However for iPP/OBT nanocomposite the endothermic peak becomes broader and slightly shifts to a high temperature range. 


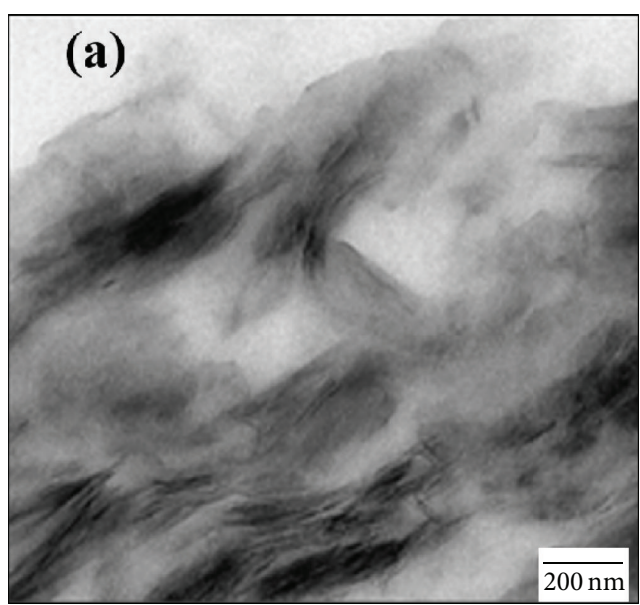

(a)

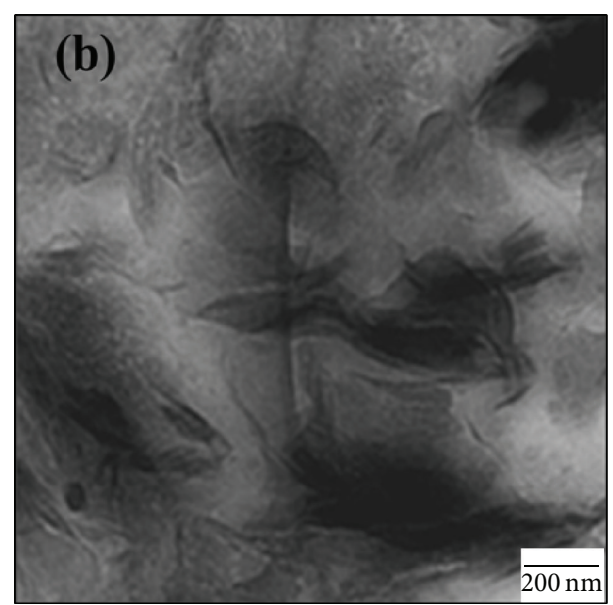

(b)

FIgURE 4: TEM micrographs of (a) iPP/OBT and (b) iPP/PBT.

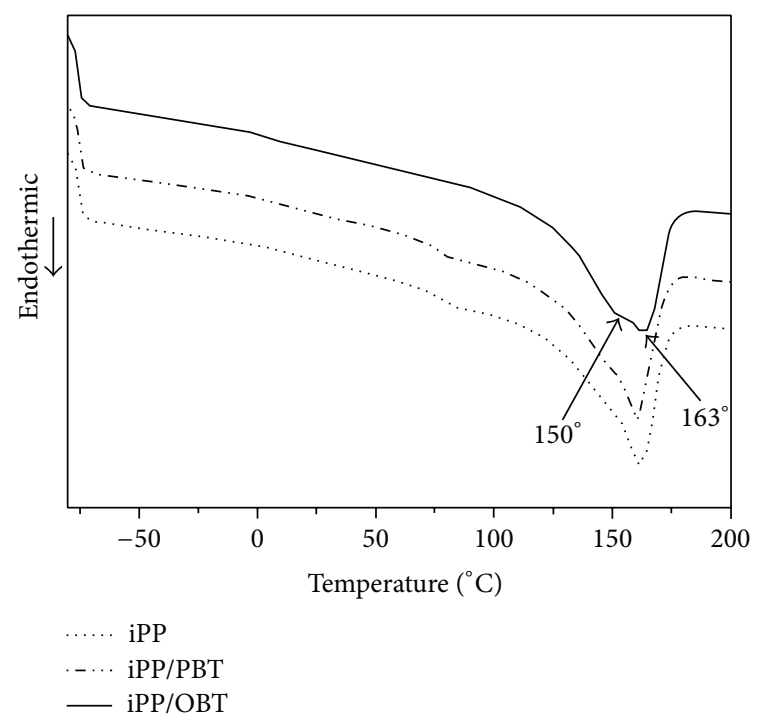

FIGURE 5: DSC melting curves of iPP and its iPP composites.

TABLE 1: DSC results of iPP and its iPP/Maghnia bentonite composites.

\begin{tabular}{lccccc}
\hline Samples & $T_{\mathrm{mp}}\left({ }^{\circ} \mathrm{C}\right)$ & $\Delta H_{m}(\mathrm{~J} / \mathrm{g})$ & $T_{c}\left({ }^{\circ} \mathrm{C}\right)$ & $\Delta H_{m}(\mathrm{~J} / \mathrm{g})$ & $\chi_{c}(\%)$ \\
\hline iPP & 160 & 76.4 & 106 & 75.8 & 52.3 \\
iPP/PBT & 161 & 77.3 & 110 & 81.6 & 55.7 \\
iPP/OBT & 163 & 86.6 & 116 & 85.1 & 62.4 \\
\hline
\end{tabular}

An endothermic shoulder also appears around $150^{\circ} \mathrm{C}$ characterizing the $\beta$ phase of iPP. In this case, the formation of the $\beta$ phase can be promoted in iPP by the OBT addition. This result is in good agreement with that obtained by XRD analysis.

From Table 1, it can be noticed that the enthalpy of fusion $\left(\Delta H_{m}\right)$ for iPP/OBT nanocomposite increases compared to that of pure iPP or iP/PBT composite and therefore the high

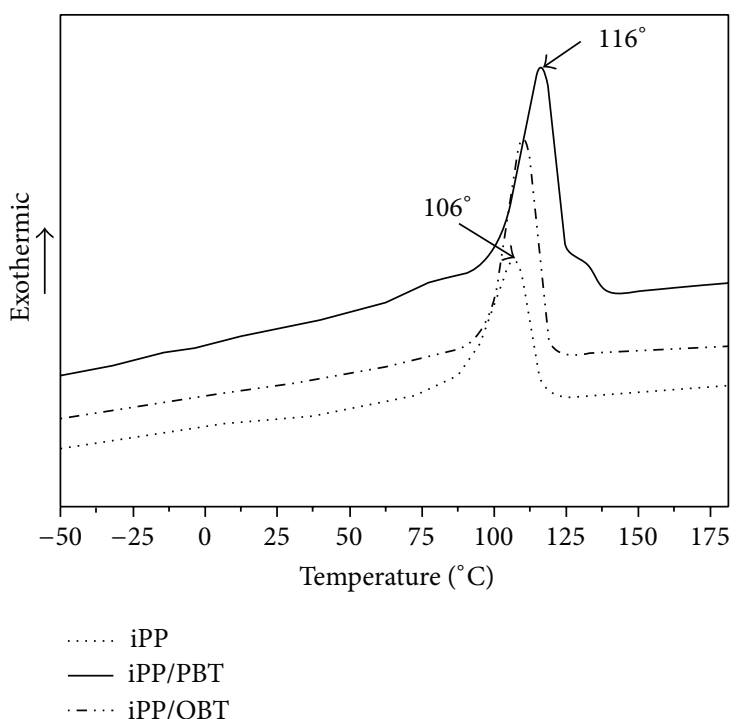

FIGURE 6: DSC crystallization curves of iPP and its iPP composites.

value of degree of $\chi$ obtained for the nanocomposite reflects an increase of iPP crystallinity as a result of the nucleation effect of the OBT $[29,30]$.

Furthermore, as the aforementioned argument that the organoclay could act as the nucleating agent and accelerate the crystal growth of the iPP polymer, the crystallization temperature of the nanocomposite was clearly enhanced compared with that of the pure iPP or IPP/PBT composite (Figure 6). Indeed, the incorporation of the oganomodified bentonite significantly increases the crystallization temperature of iPP from $106^{\circ}$ to $116^{\circ} \mathrm{C}$. This suggests that the OBT nanoparticles impart a high efficiency to the heterogeneous nucleation of iPP.

It is known that the organoclay is an effective nucleating agent due to the high surface area of silicate platelets and their chemical affinity for the polymer, which induce a nucleation 


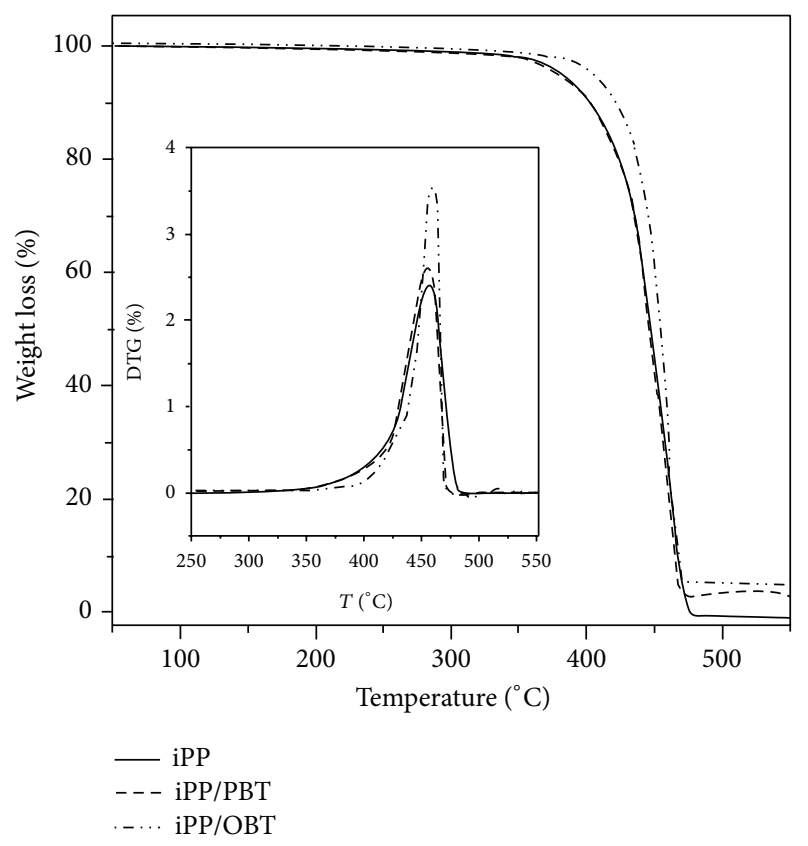

FIgURE 7: TGA and DTG thermograms of iPP, iPP/PBT, and iPP/OBT.

and lamellar ordering effect. For iPP/OBT nanocomposite, $5 \mathrm{wt} \%$ of organoclay act as nucleating agent, heighten the crystallization rate, and induce the crystallization at higher temperature compared with that of the pure iPP, whereas, for $\mathrm{iPP} / \mathrm{PBT}$ composite, according to the XRD and TEM results, PBT layers are not totally intercalated by the polymer chains, prefer to aggregate, which could confine the mobility of the polymer chains to rearrangement and forming of crystal grains, and finally induced the decrease of the crystallization temperature of the iPP/PBT composite but remains higher than that of the pristine iPP.

4.3.2. TGA Analysis. Figure 7 shows the mass loss (TG\%) and the derivative mass loss (DTG) curves of iPP and its nanocomposites at $10^{\circ} \mathrm{C} / \mathrm{min}$ heating rate. Typical TGA thermogram of weight loss as a function of temperature for virgin iPP and its nanocomposites can be seen. Degradation of both iPP and iPP/nanoclay materials was performed at one-stage process. It is obvious that iPP and its nanocomposites exhibited a relatively good thermostability, since no remarkable mass loss occurred until $335^{\circ} \mathrm{C}(<0.5 \%)$.

Pure iPP begins to degrade at about $425^{\circ} \mathrm{C}$. Its thermal degradation initiated primarily by thermal scissions of C-C chain bonds accompanied by transfer of hydrogen at the site of scission [31]. The initial decomposition temperature $T_{\text {onset }}$ (calculated by bitangent method from TGA curves) and the peak decomposition temperature at maximum weight loss rate from DTG curves $T_{\max }$ and residues $(\mathrm{Re})$ at $580^{\circ} \mathrm{C}$ are summarized in Table 2.

Temperature $T_{\text {onset }}$ of iPP/PBT is about $4^{\circ} \mathrm{C}$ higher than that of virgin iPP. The amount (5\%) of pure clay in iPP does not make a significant enhancement in thermal stability of this hybrid system. This is primarily due to the absence of
TABLE 2: Thermogravimetric parameters of iPP/Maghnia bentonite nanocomposites.

\begin{tabular}{lccc}
\hline Samples & $T_{\text {onset }}\left({ }^{\circ} \mathrm{C}\right)$ & $T_{\max }\left({ }^{\circ} \mathrm{C}\right)$ & $\operatorname{Re}(\%)$ \\
\hline iPP & 425 & 453 & 0 \\
iPP/PBT & 429 & 455 & 3 \\
iPP/OBT & 438 & 462 & 5 \\
\hline
\end{tabular}

surfactant on the surface of nanoclay and hence there was a low diffusion of polymer into the nanoclay resulting in agglomeration. However, an increase in the initial decomposition temperature of $13^{\circ} \mathrm{C}$ was noticed when OBT was added in $\mathrm{iPP} / \mathrm{OBT}$ nanocomposite. This increase was attributed to the barrier effect of OBT layers dispersed in the isotactic polypropylene matrix.

As seen from the peak of the first derivative, the temperature, at which iPP decomposition rate is the highest, is $T_{\max }=453^{\circ} \mathrm{C}$ for a $10^{\circ} \mathrm{C} / \mathrm{min}$ heating rate. In the case of iPP/PBT nanocomposites, the main degradation peak remains basically unchanged compared to pure iPP (Table 2). However, an improved thermal stability was obtained with iPP/OBT nanocomposite due to the incorporation of clay particles into iPP matrix, which could enhance thermal stability of iPP [32], as seen from Table 2. A residue (Re) about $5 \%$ is obtained with iPP/OBT nanocomposite compared to $0 \%$ of its corresponding virgin polymer.

4.3.3. Thermal Degradation of Pure iPP and Its Nanocomposites ( $i P P / P B T$ and $i P P / O B T$ ). For all samples, degradation was studied through nonisothermal measurements at different heating rates $\left(5,10,20,30\right.$, and $\left.40^{\circ} \mathrm{C}\right)$. In Figure 8, mass loss at different heating rates for $\mathrm{iPP} / \mathrm{POBT}$ nanocomposites is shown. As it could be noticed, $T_{\text {onset }}$ was gradually shifted to higher values for most heating rates for all samples. This increase in thermal decomposition temperatures of pure iPP is caused by heat hysteresis.

In reference to Yuan et al. works [33], we attempted to eliminate the influence of heating rates on thermal hysteresis, by following the variation of $T_{\max }$ as a function of heating rate. As shown in Figure 9, $T_{\max }$ of iPP and its nanocomposites increased linearly along with the heating rates $(\beta)$. The relationship between $T_{\max }$ and $\beta$ can be expressed in the following equation:

$$
T_{\max }=T_{\max }^{0}+A \beta
$$

where $T_{\max }^{0}$ is the equilibrium peak thermal decomposition temperature assuming that the heating rate equals $0^{\circ} \mathrm{C} / \mathrm{min}$ and $A$ is the rate constant.

$T_{\max }$ and $A$ value of iPP/OBT nanocomposite are higher than those of pure iPP. These results suppose an improvement of OBT barrier effect. The insertion of organomodified OBT in the iPP matrix is likely to enhance its thermal stability.

4.3.4. Determination of Activation Energy. In order to deeply analyze the effect of the incorporation of pure bentonite or organically modified bentonite into iPP matrix on the degradation mechanism of iPP, it is important to evaluate 


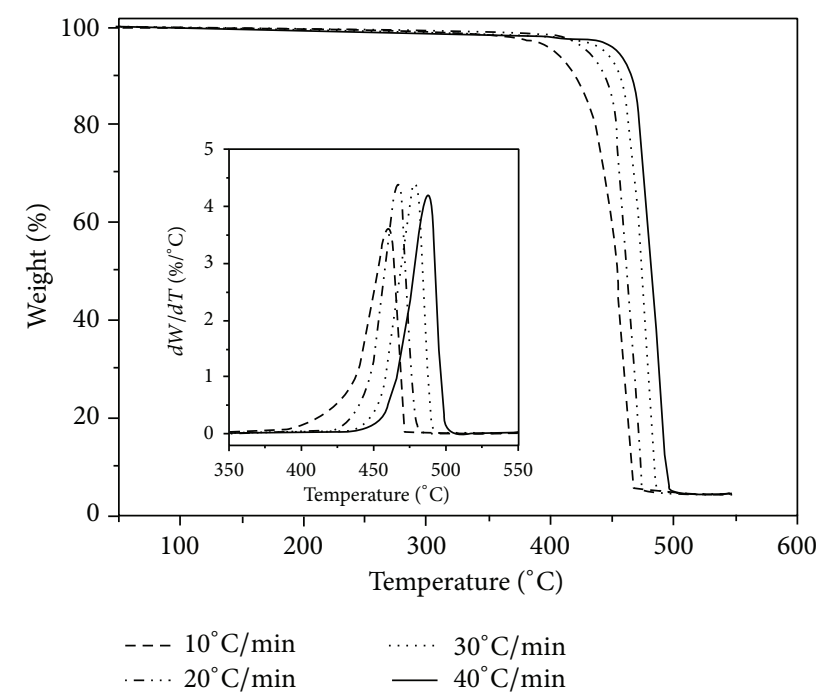

FIGURE 8: Mass loss (\%) curves and derivative mass loss curves at different heating rates of $\mathrm{PP} / \mathrm{OBT}$ nanocomposite.

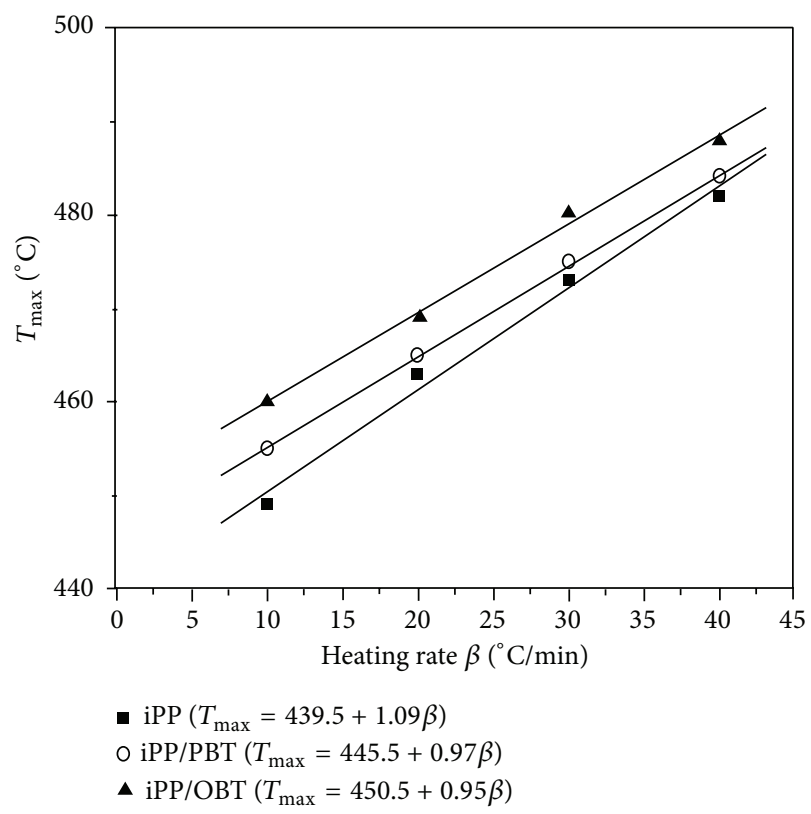

FIgURE 9: Plot of $T_{\max }$ versus heating rates of iPP and its iPP/Maghnia bentonite nanocomposites.

the kinetic parameters (activation energy $E_{a}$ and preexponential factor $A$ ).

The activation energy of degradation of pure iPP and $\mathrm{iPP} / \mathrm{PBT}$ or IPP/OBT nanocomposites was first estimated by the well-known equation of Ozawa, Flynn, and Wall (OFW) and then by the new method developed by Tang.

The activation energy determined from OFW method increased with the degree of conversion for pure iPP and $\mathrm{iPP} / \mathrm{PBT}$ or iPP/OBT nanocomposites (Figure 10), which

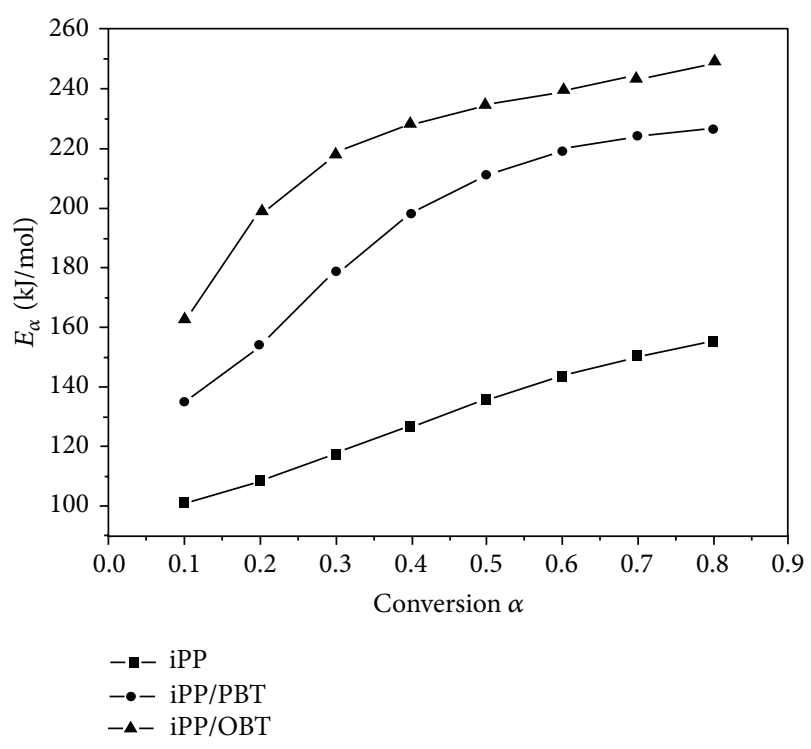

Figure 10: Dependence of the activation energy $E_{a}$ on the degree of the conversion $\alpha$ of the mass loss, as calculated with the OFW method for the different nanocomposites.

should be ascribed to the nature of random scission degradation and the differences in deviation from stationary reaction state at the different heating rates. In addition, activation energies of $\mathrm{iPP} / \mathrm{PBT}$ or iPP/OBT nanocomposites were much higher than those of pure iPP. This is an indication that the incorporation of nanoclay into the iPP matrix improved iPP thermal stability. These results are in entire agreement determined by Vassiliou et al. [34]. It was reported that the presence of intercalated clay nanoparticles has a stronger stabilizing effect in the early stage. The plate nanoparticles form a more effective diffusion barrier and thus hinder diffusion of formed gasses during iPP thermal degradation [35].

For comparative purpose, activation energy was then calculated using Tang's method. Data of apparent activation energies for pure iPP, iPP/PBT, and iPP/OBT nanocomposites were illustrated in Figure 11.

Activation energies of iPP/Maghnia bentonite nanocomposites are much higher than that of pure iPP and became much more important when organically bentonite was added to iPP.

This is mainly due to the presence of surfactant which widely separated the clay layers and hence allows a high diffusion of polymer into the nanoclay. The plate nanoparticles form a more effective diffusion barrier and thus hinder diffusion of formed gasses during iPP thermal degradation. These results suppose that the shielding effect of the Maghnia bentonite layers could increase the activation energy of the polymer matrix thermal degradation.

4.4. Mechanical Properties. In the last part of this contribution, the effect of the addition of unmodified or organically modified bentonite on the mechanical properties of iPP nanocomposites was also studied and shown in Table 3. 


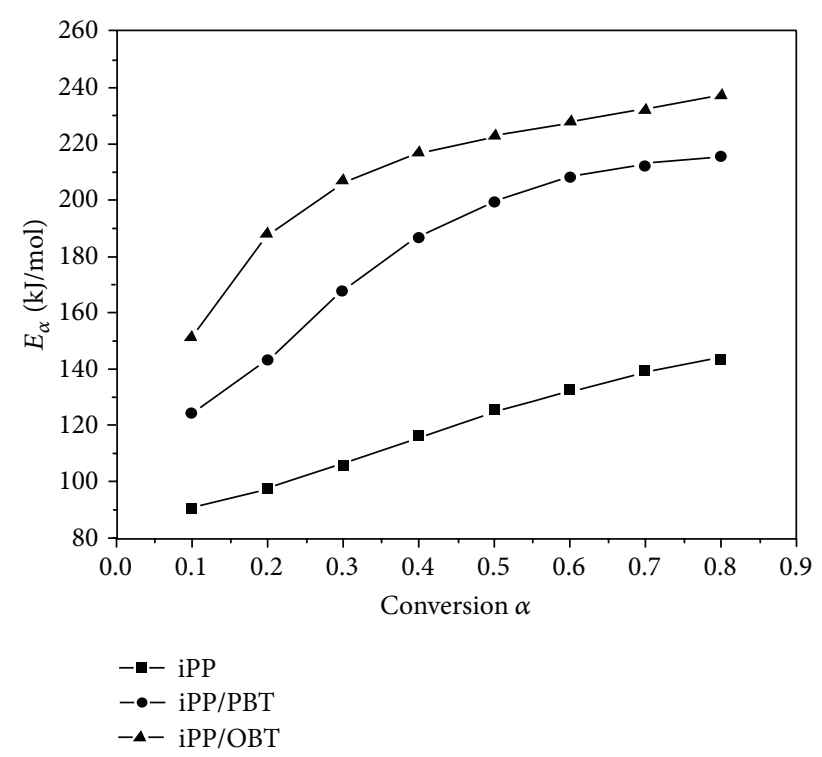

FIgURE 11: Dependence of the activation energy $E_{\alpha}$ on the degree of the conversion $\alpha$ of the mass loss, as calculated with the Tang method for the different nanocomposites.

TABle 3: Physical and mechanical properties of iPP and its iPP/Algerian bentonite nanocomposites.

\begin{tabular}{lccc}
\hline Samples & $\begin{array}{c}\text { Young's modulus } \\
E(\mathrm{MPa})\end{array}$ & $\begin{array}{c}\text { Strength } \\
\sigma(\mathrm{MPa})\end{array}$ & $\begin{array}{c}\text { Elongation at } \\
\text { break } \varepsilon(\%)\end{array}$ \\
\hline iPP & $1045.0( \pm 10.4)$ & $25.7( \pm 0.6)$ & $650.0( \pm 38.0)$ \\
iPP/PBT & $1030.0( \pm 5.5)$ & $26.6( \pm 0.8)$ & $600.0( \pm 45.0)$ \\
iPP/OBT & $1305.5( \pm 20.2)$ & $30.5( \pm 1.2)$ & $350.0( \pm 25.0)$ \\
\hline
\end{tabular}

Compared to pure iPP, nanocomposites have higher mechanical properties particularly when OBT was used $[36,37]$. This might be due to OBT surface which is much more hydrophobic than PBT surface. Therefore, OBT has good thermodynamical compatibility with the polymer matrix, which leads to improvement in stiffness [38].

\section{Conclusion}

The purpose of this contribution is the elaboration of nanocomposites by melt intercalation using bentoniteoriginated from Algeria. Higher intercalation level was obtained for the composite prepared using organomodified bentonite compared to the one obtained with pure bentonite. XRD results showed that no significant change induced by the nanofillers incorporation has been noticed on the iPP crystal structure. The $\alpha$-crystalline form dominated for the two hybrid materials. It should be noted also that in iPP/OBT composite both monoclinic $\alpha$ and hexagonal $\beta$ forms exist. TEM micrographs of iPP/Maghnia bentonite confirmed in agreement with XRD the formation of mainly intercalated nanocomposite structures.

Both XRD and DSC analyses evidenced an increase in the iPP crystallinity induced by clay incorporation. An improvement of iPP thermal stability was noticed by TGA.
Activation energies of both iPP/PBT and iPP/OBT nanocomposites have increased compared to pure iPP, which is due to the incorporation of clay particles into iPP matrix, and consequently improve iPP thermal stability. Tensile tests have shown that nanomaterials have higher mechanical properties particularly when OBT is used for nanocomposites elaboration.

\section{Conflict of Interests}

The authors declare that there is no conflict of interests regarding the publication of this paper.

\section{References}

[1] A. Vassiliou, D. Bikiaris, K. Chrissafis, K. M. Paraskevopoulos, S. Y. Stavrev, and A. Docoslis, "Nanocomposites of isotactic polypropylene with carbon nanoparticles exhibiting enhanced stiffness, thermal stability and gas barrier properties," Composites Science and Technology, vol. 68, no. 3-4, pp. 933-943, 2008.

[2] S. S. Ray and M. Okamoto, "Polymer/layered silicate nanocomposites: a review from preparation to processing," Progress in Polymer Science, vol. 28, no. 11, pp. 1539-1641, 2003.

[3] X.-L. Jiang, J.-B. Bao, T. Liu, L. Zhao, Z.-M. Xu, and W.-K. Yuan, "Microcellular foaming of polypropylene/clay nanocomposites with supercritical carbon dioxide," Journal of Cellular Plastics, vol. 45, no. 6, pp. 515-538, 2009.

[4] H. Nathani, A. Dasari, and R. D. K. Misra, "On the reduced susceptibility to stress whitening behavior of melt intercalated polybutene-clay nanocomposites during tensile straining," Acta Materialia, vol. 52, no. 11, pp. 3217-3227, 2004.

[5] E. Manias, A. Touny, L. Wu, K. Strawhecker, B. Lu, and T. C. Chung, "Polypropylene/montmorillonite nanocomposites. Review of the synthetic routes and materials properties," Chemistry of Materials, vol. 13, no. 10, pp. 3516-3523, 2001.

[6] W. Zheng, X. Lu, C. L. Toh, T. H. Zheng, and C. He, "Effects of clay on polymorphism of polypropylene in polypropylene/clay nanocomposites," Journal of Polymer Science B: Polymer Physics, vol. 42, no. 10, pp. 1810-1816, 2004.

[7] C. J. Perez and V. A. Alvarez, "Overall crystallization behavior of polypropylene-clay nanocomposites; effect of clay content and polymer/clay compatibility on the bulk crystallization and spherulitic growth," Journal of Applied Polymer Science, vol. 114, no. 5, pp. 3248-3260, 2009.

[8] M. A. Pérez, L. B. Rivas, S. M. Rodríguez, Á. Maldonado, and C. Venegas, "Polypropylene/clay nanocomposites. Synthesis and characterization," Journal of the Chilean Chemical Society, vol. 55 , no. $4,2004$.

[9] M. J. Solomon and A. Somwangthanaroj, "Intercalated polypropylene nanocomposites," Dekker Encyclopedia of Nanoscience and Nanotechnology, 1483.

[10] J.-D. He, M. K. Cheung, M.-S. Yang, and Z. Qi, “Thermal stability and crystallization kinetics of isotactic polypropylene/organomontmorillonite nanocomposites," Journal of Applied Polymer Science, vol. 89, no. 12, pp. 3404-3415, 2003.

[11] T. Kashiwagi, E. Grulke, J. Hilding, R. Harris, W. Awad, and J. Douglas, "Thermal degradation and flammability properties of poly(propylene)/carbon nanotube composites," Macromolecular Rapid Communications, vol. 23, no. 13, pp. 761-765, 2002.

[12] C. Silvestre, S. Cimmino, M. Raimo, C. Carfagna, V. Capuano, and R. Kotsilkova, "Effect of clay/diamond and clay/carbon 
nanosystems on structure-properties relationships of iPP," Journal of Polymer Science Part B: Polymer Physics, vol. 42, pp. 34283438, 2004.

[13] S. Bouhelal, M. E. Cagiao, S. Khellaf et al., "Nanostructure and microechanical properties of reversibly crosslinked isotactic polypropylene/clay composites," Journal of Applied Polymer Science, vol. 115, no. 5, pp. 2654-2662, 2010.

[14] L. Raka, A. Sorrentino, and G. Bogoeva-Gaceva, "Isothermal crystallization kinetics of polypropylene latex-based nanocomposites with organo-modified clay," Journal of Polymer Science B: Polymer Physics, vol. 48, no. 17, pp. 1927-1938, 2010.

[15] K. Chrissafis, K. M. Paraskevopoulos, S. Y. Stavrev, A. Docoslis, A. Vassiliou, and D. N. Bikiaris, "Characterization and thermal degradation mechanism of isotactic polypropylene/carbon black nanocomposites," Thermochimica Acta, vol. 465, no. 1-2, pp. 6-17, 2007.

[16] L. Wang and J. Sheng, "A kinetic study on the thermal degradation of polypropylene/attapulgite nanocomposites," Journal of Macromolecular Science B: Physics, vol. 45, no. 1, pp. 1-11, 2006.

[17] J. Zhu, F. M. Uhl, A. B. Morgan, and C. A. Wilkie, "Studies on the mechanism by which the formation of nanocomposites enhances thermal stability," Chemistry of Materials, vol. 13, no. 12, pp. 4649-4654, 2001.

[18] A. Habi, S. Djadoun, and Y. Grohens, "Morphology and thermal behavior of organo-bentonite clay/poly(styreneco-methacrylic acid)/poly(isobutyl methacrylate-co-4vinylpyridine) nanocomposites," Journal of Applied Polymer Science, vol. 114, no. 1, pp. 322-330, 2009.

[19] B. Monasse and J. M. Haudin, "Growth transition and morphology change in polypropylene," Colloid \& Polymer Science, vol. 263, no. 10, pp. 822-831, 1985.

[20] T. A. Ozawa, "New method of analyzing thermogravimetric data," Bulletin of the Chemical Society of Japan, vol. 38, no. 11, pp. 1881-1886, 1965.

[21] J. H. Flynn and L. A. Wall, "A quick direct method for the determination of activation energy from thermogravimetric data," Polymer Letters, vol. 4, pp. 323-328, 1966.

[22] W. Tang, Y. Liu, H. Zhang, and C. Wang, "New approximate formula for Arrhenius temperature integral," Thermochimica Acta, vol. 408, no. 1-2, pp. 39-43, 2003.

[23] X. Zhang, M. Yang, Y. Zhao et al., "Polypropylene/montmorillonite composites and their application in hybrid fiber preparation by melt-spinning," Journal of Applied Polymer Science, vol. 92, no. 1, pp. 552-558, 2004.

[24] J. Varga, " $\beta$-modification of isotactic polypropylene: preparation, structure, processing, properties, and application," Journal of Macromolecular Science, vol. 41, no. 4-6, pp. 1121-1171, 2002.

[25] J. Varga and J. Karger-Kocsis, "Rules of supermolecular structure formation in sheared isotactic polypropylene melts," Journal of Polymer Science B: Polymer Physics, vol. 34, no. 4, pp. 657670, 1996.

[26] B. Rozanski, E. Monasse, A. Szkudlarek et al., "Shear-induced crystallization of isotactic polypropylene based nanocomposites with montmorillonite," European Polymer Journal, vol. 45, no. 1, pp. 88-101, 2009.

[27] J. Varga, "Supermolecular structure of isotactic polypropylene," Journal of Materials Science, vol. 27, no. 10, pp. 2557-2579, 1992.

[28] D. N. Bikiaris, G. Z. Papageorgiou, E. Pavlidou, N. Vouroutzis, P. Palatzoglou, and G. P. Karayannidis, "Preparation by melt mixing and characterization of isotactic polypropylene/ $\mathrm{SiO}_{2}$ nanocomposites containing untreated and surface-treated nanoparticles," Journal of Applied Polymer Science, vol. 100, no. 4, pp. 2684-2696, 2006.

[29] C. Hao, Y. Zhao, A. He et al., "Investigation on the melt spinning fibers of PP/organoclay nanocomposites prepared by in-situ polymerization," Journal of Applied Polymer Science, vol. 116, no. 3, pp. 1384-1391, 2010.

[30] S. A. Ahmad Ramazani, F. Tavakolzadeh, and H. Baniasadi, "Synthesis of polypropylene/clay nanocomposites using bisupported ziegler-natta catalyst," Journal of Applied Polymer Science, vol. 115, no. 1, pp. 308-314, 2010.

[31] S. L. Madorsky, Thermal Degradation of Organic Polymers, chapter 4, Wiley-Interscience, New York, NY, USA, 1964.

[32] X. Xu, Y. Ding, F. Wang et al., "Effects of silane grafting on the morphology and thermal stability of poly(ethylene terephthalate)/Clay nanocomposites," Polymer Composites, vol. 31, no. 5, pp. 825-834, 2010.

[33] X. Yuan, C. Li, G. Guan, Y. Xiao, and D. Zhang, "Thermal degradation investigation of poly(ethylene terephthalate)/fibrous silicate nanocomposites," Polymer Degradation and Stability, vol. 93, no. 2, pp. 466-475, 2008.

[34] A. A. Vassiliou, K. Chrissafis, and D. N. Bikiaris, "In situ prepared PET nanocomposites: effect of organically modified montmorillonite and fumed silica nanoparticles on PET physical properties and thermal degradation kinetics," Thermochimica Acta, vol. 500, no. 1-2, pp. 21-29, 2010.

[35] K. Wang, S. Liang, J. Deng et al., “The role of clay network on macromolecular chain mobility and relaxation in isotactic polypropylene/organoclay nanocomposites," Polymer, vol. 47, no. 20, pp. 7131-7144, 2006.

[36] J. A. Tarapow, C. R. Bernai, and V. A. Alvarez, "Mechanical properties of polypropylene/clay nanocomposites: effect of clay content, polymer/clay compatibility, and processing conditions," Journal of Applied Polymer Science, vol. 111, no. 2, pp. 768-778, 2009.

[37] S. K. Sharma and S. K. Nayak, "Surface modified clay/polypropylene (PP) nanocomposites: effect on physicomechanical, thermal and morphological properties," Polymer Degradation and Stability, vol. 94, no. 1, pp. 132-138, 2009.

[38] M. V. Burmistr, K. M. Sukhyy, V. V. Shilov et al., "Synthesis, structure, thermal and mechanical properties of nanocomposites based on linear polymers and layered silicates modified by polymeric quaternary ammonium salts (ionenes)," Polymer, vol. 46, no. 26, pp. 12226-12232, 2005. 

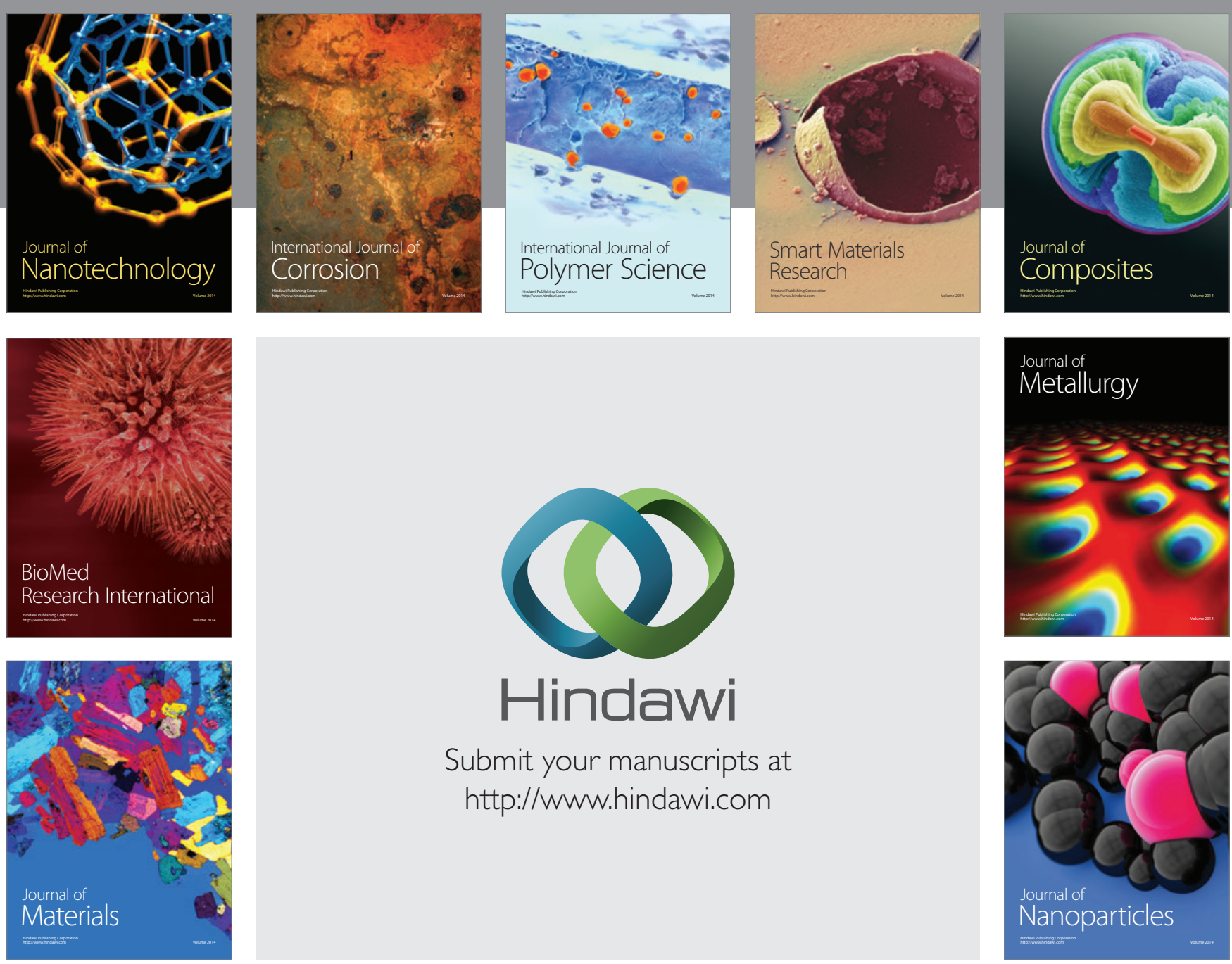

Submit your manuscripts at http://www.hindawi.com
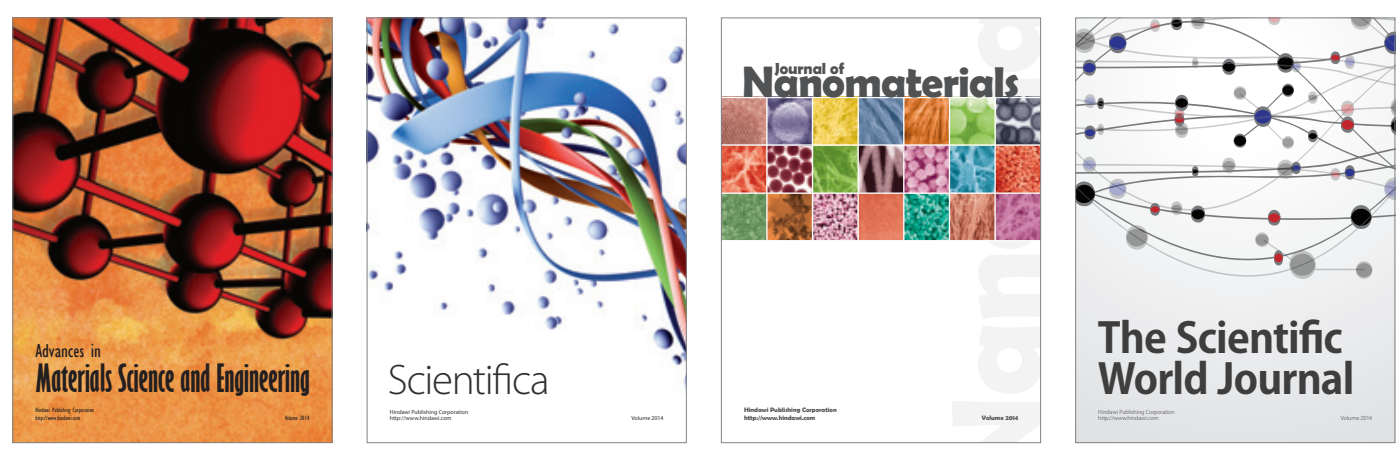

\section{The Scientific World Journal}
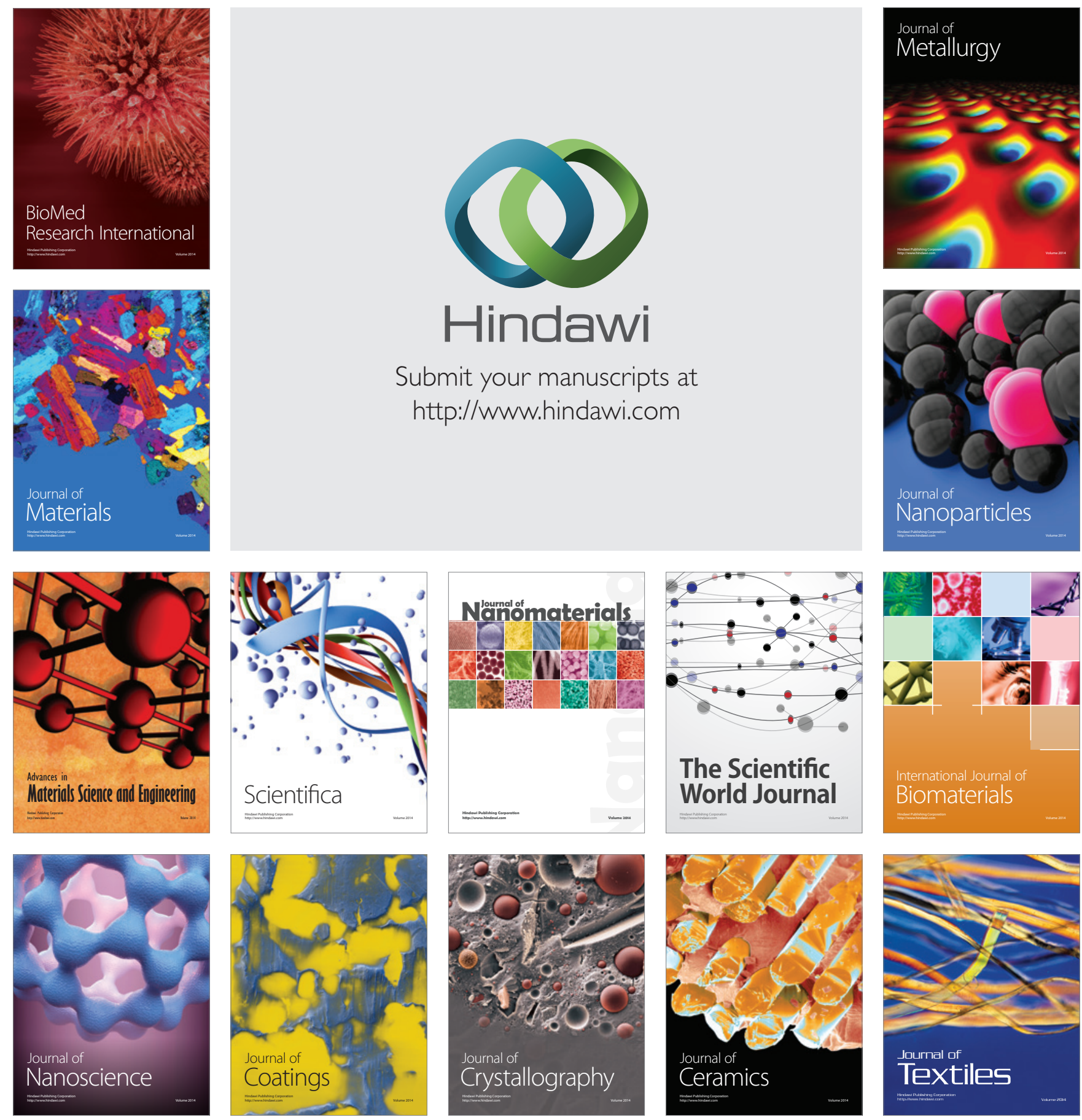